\title{
Diphencyprone as a therapeutic option in cutaneous metastasis of melanoma. A single-institution experience*
}

\author{
Ivana Lameiras Gibbons ${ }^{1}$ \\ Eduardo Bertolli ${ }^{1}$ \\ Clovis Antonio Lopes Pinto ${ }^{3}$
}

\author{
Marina Sonagli \\ Mariana Petaccia de Macedo $^{3}$ \\ João Pedreira Duprat Neto ${ }^{1}$
}

DOI: http:/ / dx.doi.org/10.1590/abd1806-4841.20187162

\begin{abstract}
Diphencyprone has been reported as a local immunotherapy for cutaneous melanoma metastases. We aim to report cases of melanoma patients treated with diphencyprone in a single Brazilian institution and highlight their outcomes. Since 2012, we have treated 16 melanoma patients with cutaneous metastases with topical diphencyprone. To date, we have had $37.5 \%$ of complete response, $25 \%$ of partial responses, and $31.25 \%$ patients without any response. Treatment was well tolerated and local toxicity was easily controlled. We believe topical diphencyprone is a feasible treatment that can be another option for treating melanoma patients, especially in cases of in-transit or extensive disease.
\end{abstract}

Keywords: Melanoma; Neoplasm metastasis; Therapeutics

Diphencyprone (DPCP) is a potent contact sensitizer that has most frequently been used as immunotherapy for cutaneous warts and alopecia areata. ${ }^{1,2}$ There are reports of DPCP combined with oral cimetidine or dacarbazine and radiotherapy to treat cutaneous melanoma metastases. ${ }^{3,4}$

Its mechanism is still unclear. Nevertheless, there are several reports in the literature presenting DPCP as an option for melanoma patients with in-transit metastases or patients with extensive or bulky disease. ${ }^{1,5}$

The largest case series comes from Australia, with 50 melanoma patients treated with DPCP. ${ }^{6}$ The initial experiences of both a British and a Canadian center were also reported with very similar results. ${ }^{5,7}$

The objective of this study is to report cases of melanoma patients treated with DPCP as a single topic agent in a single Brazilian institution, and to highlight their outcomes regarding tumor response.

After being informed about the potential risks and benefits of the treatment, all patients signed the informed written consent. DPCP was first used in our institution in 2012, following the methodology previously reported in the literature. ${ }^{1}$ Briefly, the patient is initially sensitized with a $2 \%$ solution of DPCP in acetone, which is applied to the arm or back, and held in contact by an occlusive dressing for 48 hours. If an eczematous reaction is seen, the patient is considered sensitized and waits for 10-14 days before starting receiving DPCP $0.005 \%$ in aqueous cream. DPCP $0.005 \%$ is then applied to the targeted melanoma lesions. The area is covered with a dressing that remains closed for 24 hours. This procedure is then repeated weekly with patient kept under observation. Whenever necessary, the concentration of DPCP is adjusted.

We performed post treatment biopsies in treated tumor areas and used standard parameters to process pathology specimens. Haematoxilin \& eosin (HE) slides were reviewed by experienced pathologists that further categorized the lesions into complete response (CR), partial response (PR), and no response (NR), according to the amount of residual tumor or presence of tissue inflammation.

Sixteen patients were treated with DPCP in the last 5 years ( 9 males, 7 females; mean age $=62.38,21-87$ years). All patients had previous diagnosis of invasive melanoma. In most cases, DPCP was used to treat in-transit disease or cutaneous metastasis. However, there were 2 cases of visceral metastasis.

Clinical follow-up examinations were performed monthly (or whenever necessary). Response evaluation was performed with biopsies in treated areas, usually after 3 months of treatment. To

Received on 12.04.2017.

Approved by the Advisory Board and accepted for publication on 19.07.2017.

* Work performed at the AC Camargo Cancer Center - São Paulo (SP), Brasil.

Financial support: None.

Conflict of interest: None.

Skin Cancer Center - AC Camargo Cancer Center - São Paulo (SP), Brazil

Oncology Residency Training Program - AC Camargo Cancer Center - São Paulo (SP), Brazil.

Department of Pathology - AC Camargo Cancer Center - São Paulo (SP), Brazil.

MAILING ADDRESS:

Eduardo Bertolli

E-mail: ebertolli@hotmail.com

(C)2018 by Anais Brasileiros de Dermatologia 

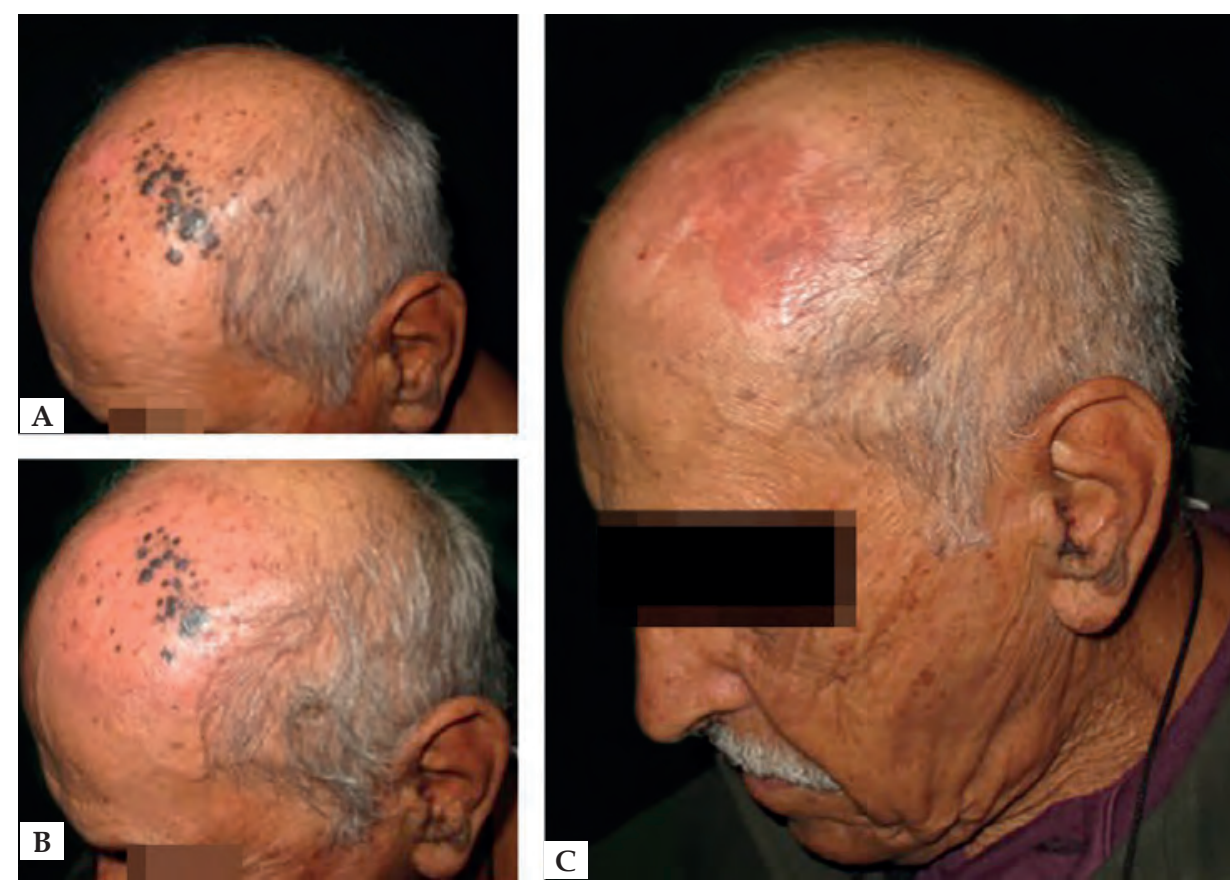

Figure 1: A - Clinical aspect before treatment. B - Three months after treatment, when biopsies were performed. C - One year after treatment, with com-

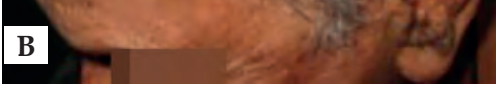
C plete clearance of the scalp lesions
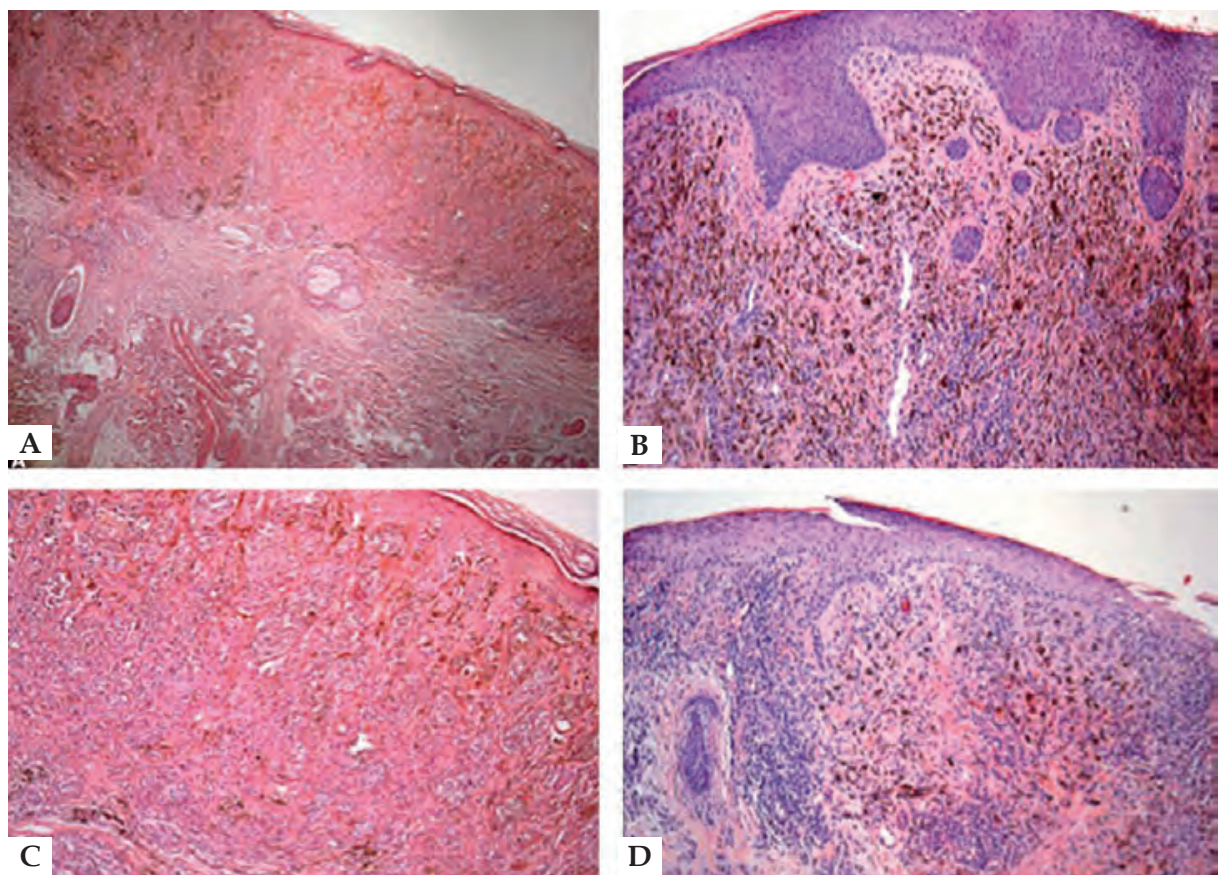

FIgURE 2: Pathological aspect before treatment - A - Hematoxylin \& eosin, X100 and C - Hematoxylin \& eosin, X200; Hematoxylin \& eosin, 3 months after treatment, showing fibrosis with an intense melanin deposits in the dermis and a chronic inflammatory infiltrate, but with no residual melanoma cells - (Hematoxylin \& eosin, X100, B and D)

date, 6 patients $(37.5 \%)$ showed CR and all of them remain under treatment. PR was seen in 4 patients (25\%). Five patients $(31.25 \%)$ showed NR and 2 of them developed disease progression. Two of the patients with NR had disease progression and 1 of them died from melanoma during the treatment. The $16^{\text {th }}$ patient has recently started his treatment.

The most common side effect was local erythema, which was initially treated with skin moisturizers. We also needed to reduce DPCP concentration to $0.0025 \%$ in 3 patients. One patient needed systemic corticosteroids and 1 needed anti-histamine therapy. We observed no harm to patients who required these other medications. Pathological assessment after treatment was very important. Although most patients still presented with cutaneous lesions, biopsies showed only pigment and melanophages (Figure 1). This pattern was seen is all patients who showed CR or PR (Figure 2).

Some patients used DPCP before systemic treatments, and some used it simultaneously. We observed no interference of DPCP in the toxicity of these treatments, including patients who underwent immunotherapies. 
Some recent investigations assessed the value of topical DPCP immunotherapy for superficial in-transit metastatic melanoma. Although its mechanism is still unclear, DPCP seems to be another therapy for melanoma patients. . $1,7,7,8$

The largest case series ever published belongs to the Melanoma Institute Australia (MIA), with 50 cases reported. ${ }^{6}$ They achieved CR in $46 \%$ of the patients with cutaneous melanoma metastasis, and PR in 38\%. In a British case series with 35 patients, 28.6\% showed CR, 31.4\% PR, and 40\% NR. ${ }^{7}$ A Canadian series with 15 patients treated with DPCP shows $13 \%$ of CR, $27 \%$ of PR, and $40 \%$ of stable disease. ${ }^{5}$

Similar results could be reproduced in our patients, albeit in smaller number. In this study, our overall response rate was $62.5 \%$. In addition, topic DPCP is easy for patients to apply, has been well tolerated so far, and is not an expensive treatment in Brazil, the same advantages reported in Australia.

\section{REFERENCES}

1. Damian DL, Shannon KF, Saw RP, Thompson JF. Topical diphencyprone immunotherapy for cutaneous metastatic melanoma. Australas $\mathrm{J}$ Dermatol. 2009;50:266-71.

2. Friedmann PS, Haddadeen C, Lai C, Healy E. In vitro human $\mathrm{T}$ cell responses to diphencyprone. Contact Dermatitis. 2017;76:251-253.

3. Harland CC, Saihan EM. Regression of cutaneous metastatic malignant melanoma with topical diphencyprone and oral cimetidine. Lancet. 1989;2:445.

4. Trefzer U, Sterry W. Topical immunotherapy with diphenylcyclopropenone in combination with DTIC and radiation for cutaneous metastases of melanoma. Dermatology. 2005;211:370-1.

5. Yeung C, Petrella TM, Wright FC, Abadir W, Look Hong NJ. Topical immunotherapy with diphencyprone (DPCP) for in-transit and unresectable cutaneous melanoma lesions: an inaugural Canadian series. Expert Rev Clin Immunol. 2017;13:383-388.

6. Damian DL, Saw RP, Thompson JF. Topical immunotherapy with diphencyprone for in transit and cutaneously metastatic melanoma. J Surg Oncol. 2014;109:308-13.

7. Moncrieff M, Fadhil M, Garioch J. Topical diphencyprone for the treatment of locoregional intralymphatic melanoma metastases (LIMMs) of the skin. The 5-Year Norwich experience. Br J Dermatol. 2016;174:1141-2.
Even though the approval of novel therapeutic approaches - such as immune checkpoint inhibition - has changed front-line management of advanced melanoma, there remains room for improvement in treatment outcomes. The association of DPCP and systemic treatments - especially with immunotherapies such as the anti-PD-1 antibody - has been also reported. ${ }^{9,10}$ Our studies revealed no increased toxicity and two patients treated under this approach showed complete response.

Some issues related to DPCP treatment remains unclear, such as the optimal duration of the treatment, development of resistance mechanisms, and existence of a predictor marker for response that could be tested prior to treatment.

This is the first report of DPCP used to treat melanoma patients from Brazil and South America. We believe the treatment is feasible and our results can be reproduced. In other words, this this may be another option for treating melanoma patients, especially for in-transit or extensive disease.
8.

Damian DL, Saw RP. Dramatic regression of cutaneous, nodal, and visceral melanoma metastases. J Am Acad Dermatol. 2011;65:665-6.

9. Fujimura T, Furudate S, Kakizaki A, Kambayashi Y, Haga T, Hashimoto A, Aiba S. Contact immunotherapy enhances the therapeutic effects of nivolumab in treating in-transit melanoma: Two cases reports. J Dermatol. 2016;43:686-9.

10. Gulati N, Carvajal RD, Postow MA, Wolchok JD, Krueger JG. Definite regression of cutaneous melanoma metastases upon addition of topical contact sensitizer diphencyprone to immune checkpoint inhibitor treatment. Exp Dermatol. 2016;25:553-4.

How to cite this article: Gibbons IL, Sonagli M, Bertolli E, Macedo MP, Pinto CAL, Duprat Neto JP. Diphencyprone as a therapeutic option in cutaneous metastasis of melanoma. A single-institution experience. An Bras Dermatol. 2018;93(2):299-301. 